\title{
Comparative Experiment of Coagulant for the Pretreatment of Coagulation Air Floatation for Slaughter Wastewater
}

\author{
Xiang $\mathrm{He}^{1, a}$, Runlei Cai ${ }^{1}$,Fan Wang ${ }^{1}$, Xuejiao Feng ${ }^{1}$ \\ ${ }^{1}$ School of Municipal and Environmental Engineering, Shenyang Jianzhu University, Shenyang, \\ 110168, China \\ aemail: syjzhexiang@163.com
}

Keywords: Slaughter Wastewater; Coagulate; Coagulant

\begin{abstract}
As a kind of high concentration organic wastewater, coagulation pretreatment for slaughter wastewater should be carried out before biological treatment process.For optimal treatment effect, the choice of coagulant was crucial.In this paper, $\mathrm{FeSO}_{4} .7 \mathrm{H}_{2} \mathrm{O}, \mathrm{FeCl}_{3}, \mathrm{Al}_{2}\left(\mathrm{SO}_{4}\right)_{3}$, PAC were taken as coagulant and PAM was taken as coagulant aid. The effect of coagulation was analyzed under different conditions.Results showed that the PAC was the best coagulant for slaughter wastewater pretreatment .This study provided reference for coagulation air floatation of slaughter wastewater pretreatment .
\end{abstract}

\section{Introduction}

The wastewater from slaughter industry present high concentration, serious pollution, the waste water produced in composition is complex and the characteristics of volatility.According to the characteristics of slaughter wastewater, there are a lot of pollutants in the form of slurry, which is the main object of physical and chemical treatment to remove [1-2].

Coagulation precipitation and coagulation air floatation are necessary to choose the appropriate coagulant and flocculant is a lot of more phyletic, the existing coagulant has two kinds of inorganic and organic.Of applied inorganic coagulant in water treatment, mainly iron and aluminium salt and its polymer [3].Aluminum salt coagulant used mainly for $\mathrm{Al}_{2}\left(\mathrm{SO}_{4}\right)_{3}$, PAC.Iron salts commonly used mainly $\mathrm{FeCl}_{3}, \mathrm{FeSO}_{4} .7 \mathrm{H}_{2} \mathrm{O}$ and PAF.This experiment through the beaker experiment considering the removal rate of $\mathrm{COD}$ and turbidity and cost to determine the use of coagulant.Coagulant aid PAM for nonionic organic polymer flocculant, plays a role of bridge can be.This experiment selected coagulants can better play and colloid particle surface charge, electric double layer compression, to reduce the potential role.But coagulant bridging ability is weak, the formation of flocs is loose, and not easy sedimentation, PAM is just made up for the inadequacy of them [4].Selection of coagulant and coagulant aid are shown in table 1:

Table1 The types of flocculant and coagulant aid

\begin{tabular}{lc}
\hline Flocculant & Coagulant aid \\
\hline $\mathrm{FeSO}_{4} \cdot 7 \mathrm{H}_{2} \mathrm{O}$ & \\
$\mathrm{FeCl}_{3}$ & PAM \\
$\mathrm{Al}_{2}(\mathrm{SO} 4)_{3}$ & \\
$\mathrm{PAC}$ & \\
\hline
\end{tabular}

\section{Comparison of Coagulants}

Six $1000 \mathrm{ml}$ beaker were numbered from left to right with 1, 2, 3, 4, 5, 6, 6 cup which all added $1000 \mathrm{ml}$ of raw water. The water was adjusted by $0.1 \mathrm{~mol} / \mathrm{L} \mathrm{NaOH}$ and $\mathrm{HCl}$ solution to maintained the $\mathrm{pH}$ slightly greater than 7.0.All of the five brakers remained at about $15{ }^{\circ} \mathrm{C} .1,2,3$, 4 beaker added FeSO4.7 H2O, FeCl3, A12 (SO4) 3, and solid PAC potions in turn which quantity were all $0.5 \mathrm{~g} / \mathrm{L}$ as 5 and 6 beaker were taken as comparison test.Under the six league blender, will lower position in central impeller into a beaker, make the raw water can be fully mixed with the coagulant, 
with $120 \mathrm{r} / \mathrm{min}$ intensity of stirring $20 \mathrm{~s}$, add $2 \mathrm{ml}$ coagulant aid after $0.1 \%$ PAM, among them, add $25 \mathrm{ml}$ distilled water (alternative to join the amount of PAM solution), 6, don't add any potions, again slowly stir $5 \mathrm{~min}$. Then stir $20 \mathrm{~min}$ with observing he amount of time, size, density and other reference of alum grain. Take the clear liquid COD as indicators to detect water effect.Experimental apparatus as shown in figure 1 .

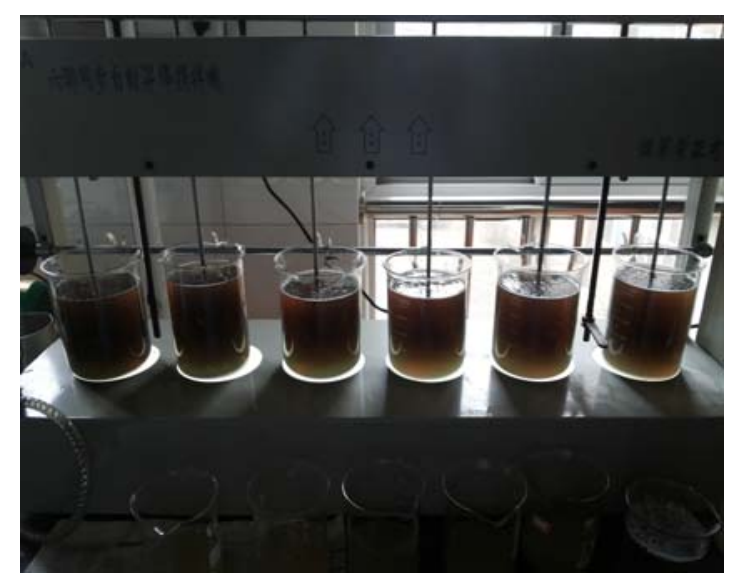

Fig 1 The drug coagulation precipitation reaction conditions after joining the drug

In the test number 1 to 4 beaker in adding flocculant and coagulant aid,the alum grain began to form after $30 \mathrm{~s}$ which appeared to about 1 min alum grain, a large number of suspended matter in raw water to precipitation to the bottom, the water in the beaker stratification gradually, the upper begin to clarify, after $20 \mathrm{~min}, 4$ state of the water in the beaker are to clarify.Testing water quality with extracting different location of the water with a syringe, the result shows in figure 2.

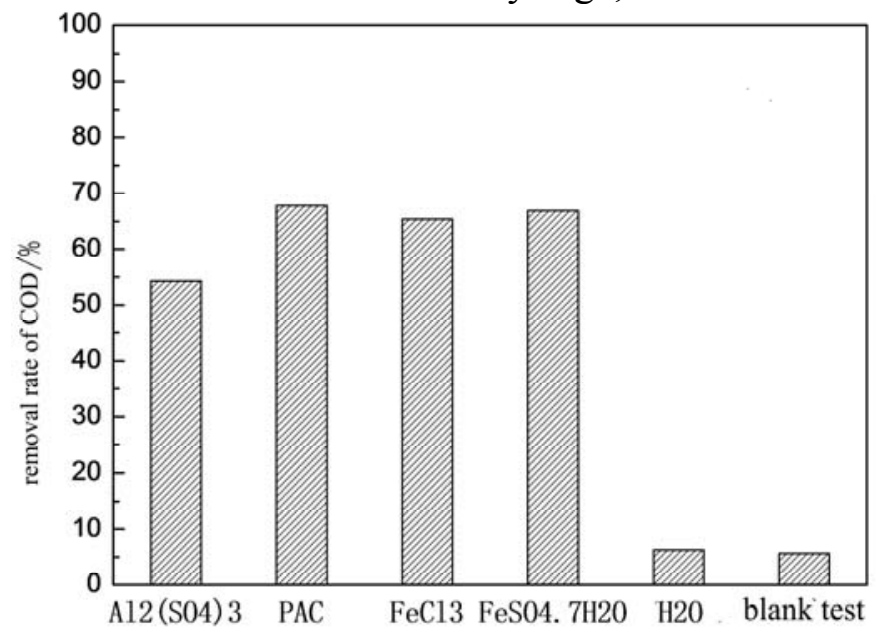

Fig 2 The influence of coagulant on COD removal

Based on the analysis of figure 2, the same original water quality was taken tested which COD was $2385 \mathrm{mg} / \mathrm{l}$. raw water after joined the flocculant, COD removal rate is over $50 \%, \mathrm{PAC}, \mathrm{FeCl}$, $\mathrm{FeSO}_{4} .7 \mathrm{H}_{2} \mathrm{O}$ removal effect is more obvious and very close.Based on the four beakers that determination of the supernatant fluid, removal rate of $\mathrm{Al}_{2}\left(\mathrm{SO}_{4}\right)_{3}$ is $54.3 \%$; the PAC removal rate is 67.8\%;removal rate of $\mathrm{FeCl}_{3}$ is $66.4 \%$;removal rate of $\mathrm{FeSO}_{4} .7 \mathrm{H}_{2} \mathrm{O}$ was $67.2 \%$. From the result , all these iron salts were similar, the coagulation effect between $\mathrm{FeSO}_{4} .7 \mathrm{H}_{2} \mathrm{O}$ in water ionization of $\mathrm{Fe}_{2}$ ${ }^{+}$only produce mononuclear complex than $\mathrm{FeCl}_{3}$ coagulation effect.But the coagulation constantly stir to dissolve in water more oxygen to accelerate its oxidation, the pollutants in the water as the generated $\mathrm{Fe}(\mathrm{OH})_{3}$ precipitation to the bottom of the cup, although longer time than $\mathrm{FeCl}_{3}$, but the upper water effect is better also.

PAC and $\mathrm{Al}_{2}\left(\mathrm{SO}_{4}\right)_{3}$ are of aluminium salt whose coagulation effect are more obvious differences. Their basic principle of coagulation, $\mathrm{Al}_{2}\left(\mathrm{SO}_{4}\right)_{3}$ hydrolysis to produce $\mathrm{Al}_{3}{ }^{+}$ions, $\mathrm{Al}(\mathrm{OH})_{3}$ gel and a variety of forms of hydrolysis of the polymer.For slaughter wastewater is not high negative charges that exist in the colloid, can take advantage of the positive charge lower 
hydrolysate in the high degree of polymerization, and to form a blood-red in slaughter wastewater such as hemoglobin, requires the positive charge higher hydrolysis product.But $\mathrm{Al}_{2}\left(\mathrm{SO}_{4}\right)_{3}$ of the hydrolysis process is relatively complex, difficult to artificially control the shape of the hydrolysate.But during the preparation of PAC can be treated by the water quality characteristics of the treated water control reaction conditions, and help to making the most appropriate polymer, when put into the water after hydrolysis can get high polymerization ion directly, so as to achieve good coagulation effect.

Comprehensive COD, turbidity, and the comparison of drug prices, it can be seen that the PAC in removal efficiency of COD and turbidity are good and the price is lower than those of other kinds of coagulant. We can get the conclusion that PAC is the best coagulant.

\section{Conclusion}

By analysising COD and turbidity of wastewater after coagulanting: COD and turbidity removal rate of PAC is $67.8 \%, 95.2 \%$ respectively.Although most of the removal rate of COD and turbidity of $\mathrm{FeSO}_{4} .7 \mathrm{H}_{2} \mathrm{O}, \mathrm{FeCl}_{3}$ is not much difference between $\mathrm{PAC}$, but take treatment effect, the economy, preservation conditions into consideration, $\mathrm{PAC}$ is chosen fot the optimum coagulant .

\section{Acknowledgement}

In this paper, the research was sponsored by the China Enviromental Protection Foundation of “123 Project"(Project No. CEPF2012-123-2-3) and Main Pollutant Emission Control and Management System Construction of Liao River Basin(Project No. 2012ZX07505-002-002).

\section{References}

[1]Chen Lie,Zhou Xingqiu,et al.The present situation and progress of slaughter wastewater treatment technology[J].Industrial Water and Wastewater,2003,06:9-13.

[2]Qiu Yulin.Slaughter wastewater microbial treatment including breeding and application research[D].Guangdong University of Technology,2005.

[3]Gaud in A M Flotation [M].2nd editoin. New York: Mc Graw Hill. 1957:126-150

[4]Chen Bimei,Su Rong.Hydrolysis acidification - coagulation air floatation - application of CASS process in slaughter wastewater treatment[J].Northern Environment,2011,04:109-110. 